\title{
Toward a New Understanding of Creative Dynamics: From One-Size-Fits-All Models to Multiple and Dynamic Forms of Creativity
}

\author{
Stephen Cummings, Chris Bilton, and dt ogilvie
}

\author{
(6 [Actually,] I'm a bigger fan of Edison than Tesla. ") \\ Elon Musk \\ Business magnate, investor, and inventor \\ CEO of Tesla Motors and SpaceX
}

\begin{abstract}
This article proposes an alternative to a managerial "best practice" approach to creativity based on the notion of creativity as a singular concept. Our alternative draws on three fundamental ideas that are emerging in different pockets of the creativity literature in a way that can be readily conceptualized and applied in practice. The first idea is that creativity is really about "creativities", or a cluster of different and discrete qualities that can be combined to suit the context in which they operate. The second is that creativity is not static: it is about "creativitying", or the action and the practice of combining these creativities, which evolve over time. The third is that being creative in organizations is not an individual act: rather, it is the multiple activities of groups as they go about creativitying.
\end{abstract}

\section{Introduction}

Creativity continues to be a widely used buzzword in management. However, managerial approaches to creativity are limited by two paradoxical conditions. First, a multiplicity of differing notions of the term "creativity" are used across different sub-fields of management. Second, an assumption is held by many managers that "creativity" is a singular concept that can be defined, managed, and directed according to a coherent set of theoretical assumptions: that there should be, in other words, a "one best way" to be creative. A conventional response to these assumptions has been to see the many one best ways as being variations of the same thing or in competition with one another. But, over the past couple of years, at successive Academy of Management conferences, we have sought to explore an alternative approach with a range of colleagues. This alternative approach is threefold. First, it refers to an emerging consensus among both organizational and cognitive researchers that sees "creativity" as a cluster of different and discrete qualities (i.e., multiple intelligences or competences). Managers, leaders, and organizations can combine these multiple "creativities" to suit their own unique contexts and considerations.
Second, we wish to promote thinking about how these creativities combine and evolve dynamically, over time. Hence, it may make more sense to think of the action and practice of "creativitying", than think of creativity as a static label. Third, rather than focusing on the individual or on individual talent as the creative "unit of analysis", as is often the case in both creative management (Prichard, 2002) and creative education (Cochrane et al., 2008), we think it might be better to examine the multiple activities of groups as they go about creativitying.

Although many of these insights are available in the creativity literature (e.g. Anderson et al., 2014; Sawyer, 2006; Sternberg, 1988), this knowledge has not, in our experience, resulted in progress in management practice. By gathering our ideas into a diagram, we hope to show how these perspectives on creativities and creativitying can be combined to achieve dynamic change in organizations. We explore this model in more detail in the next section of the article, arguing first that creativity derives from multiple creativities, not from a singular property, second that creativity is dynamic (something we do) rather than static (something we have). These two perspectives combine in a third argu- 


\section{Toward a New Understanding of Creative Dynamics}

\section{Stephen Cummings, Chris Bilton, and dt ogilvie}

ment, that creativity occurs through dynamic group behaviour (teams and systems) or "creative dynamics". Each of these perspectives is developed successively in the remaining sections of the article. As noted above, most of these insights can be located separately in existing literature on creativity; our model attempts to gather them together in a combined model that can inform management practice and deliver creative outcomes in organizations.

\section{A Matrix for Promoting a New Understanding of Creative Dynamics}

One of the most creative and inspirational writers in management is Karl Weick. One of his most compelling ideas on the way in which thinking about strategy became bogged down in the 1980s was outlined in a book chapter called "Substitutes for Strategy" (Weick, 1987). Here, Weick argued that strategy did not exist in strategic plans, even though when asked what an organization's strategy was, people often pointed to the plan that was thought to precede actions. Rather, a strategy emerged, Weick suggested, as groups took action. And, through acting in and interacting with their environment, they developed a clear orientation and at once became animated to achieve and further develop the goals that this growing orientation brought into view (Weick, 1987).

Weick illustrated this idea through a now-famous tale (albeit likely an allegorical one: see Basboll, 2010) of a group of Hungarian soldiers stranded in the mountains after an unanticipated snowstorm whited out what was supposed to be a routine training exercise. Paraphrasing Weick (1987):

The young lieutenant of a Hungarian detachment in the Alps sent a reconnaissance unit into the icy wilderness. It began to snow immediately, and unexpectedly continued to snow for two days. The unit did not return. The lieutenant feared that he had dispatched his own people to their death. However, on the third day, the unit came back. Where had they been? How had they made their way? "Yes," they said: "We considered ourselves lost and waited for the end. We did not have any maps, compasses, or other equipment with which to ascertain our position or a probable route out. But then one of us found an old tattered map in a seldom used pocket. That calmed us down. The map did not seem to quite fit the terrain but eventually we discovered our bearings. We followed the map down the mountain and after a few wrong turns eventually found our way." The lieutenant borrowed the map and had a good look at it. "This isn't a map of the Alps", he said. "It's a map of the Pyrenees!" (Cummings \& Wilson, 2003; Swieringa \& Weick, 1982; Weick, 1987).

The tale illustrates that strategy does not come from a plan or a map; action may be inspired by these things (even if they are inaccurate or out of date in their characterization of the environment), but strategy happens as people start acting. Through acting in relation to an environment, they start learning, and through this learning, they start recalibrating, and thus continue to act and react.

In other works (e.g., Cummings \& Wilson, 2003), we have sought to illustrate the interplay and development of Weick's two substitutes for strategy - orientation and animation - in a diagram or, more exactly, a two-bytwo matrix, as shown in Figure 1.

We continue to use this matrix as a framework for checking the validity of the effective use of other strategy frameworks. If the strategy developed does not create a clear sense of orientation among those who have to implement it, and animate them to enact this orientation, then it may not help create the desired outcome.

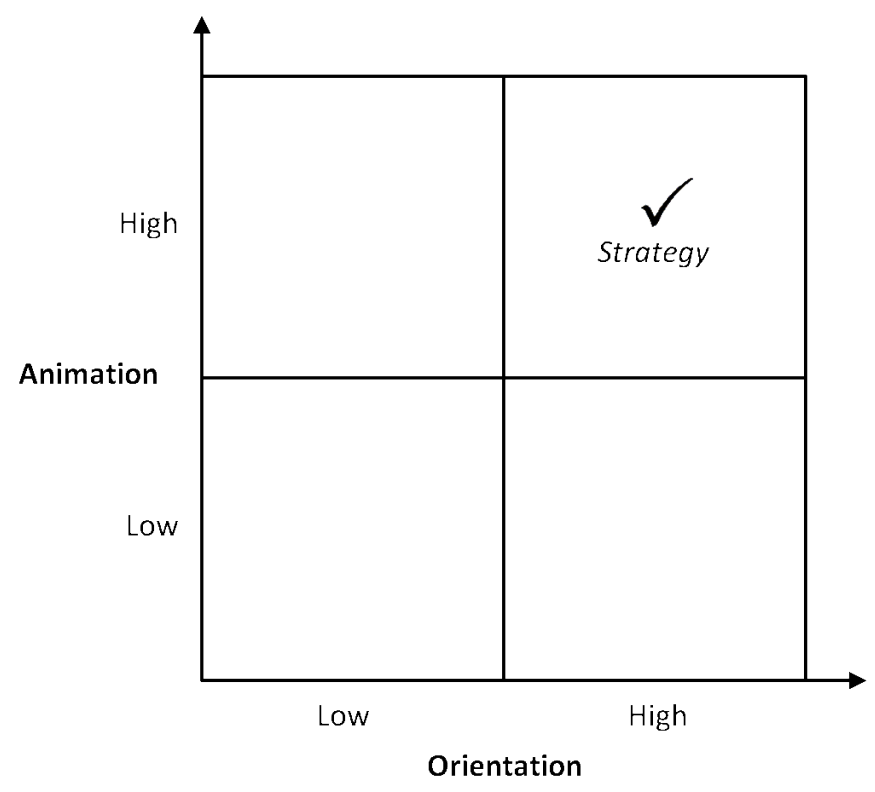

Figure 1. Strategy as the combination of increased orientation and animation (Adapted with permission from Cummings \& Angwin, 2015) 


\section{Toward a New Understanding of Creative Dynamics}

\section{Stephen Cummings, Chris Bilton, and dt ogilvie}

Our purpose for drawing on Weick's substitutes and its presentation in a two-by-two matrix is to promote three ways for thinking differently about creativity, and by doing so, raise awareness about a need to move beyond creativity as a singular, static term directed toward the individual.

Although talk of creativity now gets people's attention in management and its many sub-fields, what people tend to associate with the term limits the value that a substantive emphasis on it could add. The matrix shown in Figure 2 illustrates how we might move away from three assumptions that are associated with the discourse of creativity in management (Prichard, 2002):

Assumption 1: Creativity is singular and there is one best way to achieve it.

Alternative: Multiple "creativities" that can be orchestrated and combined.

Assumption 2: Creativity is static. It is a noun describing a subject or an adjective describing an object or a set of characteristics, not an active verb.

Alternative: "Creativitying" as a verb, valued for what it does (effects) rather than for what it is (properties).

Assumption 3: Managers tend to think of creative properties as belonging to individuals rather than to groups.

Alternative: "Creative Dynamics", in which groups combine multiple creativities to achieve dynamic effects (creative outcomes).

In the sections that follow, we discuss each of these assumptions and alternatives in more detail, and in so doing, we show how we might set a course to a new approach: by orienting eastwards on the x-axis; animating or giving life to our thinking about creativity by moving upwards on the y-axis; and by combining both orienting and animating in a diagonal line stretching north-eastwards, plotting a course towards "creative dynamics".

\section{Orienting Eastwards: From Singular Creativity to Multiple Creativities}

A PhD student we spoke to recently had an epiphany. His project, sponsored by one of the world's largest advertising agencies, sought to contrast the creative process in one of their major Western offices with those in the relatively new office in Beijing. The aim was to ob-

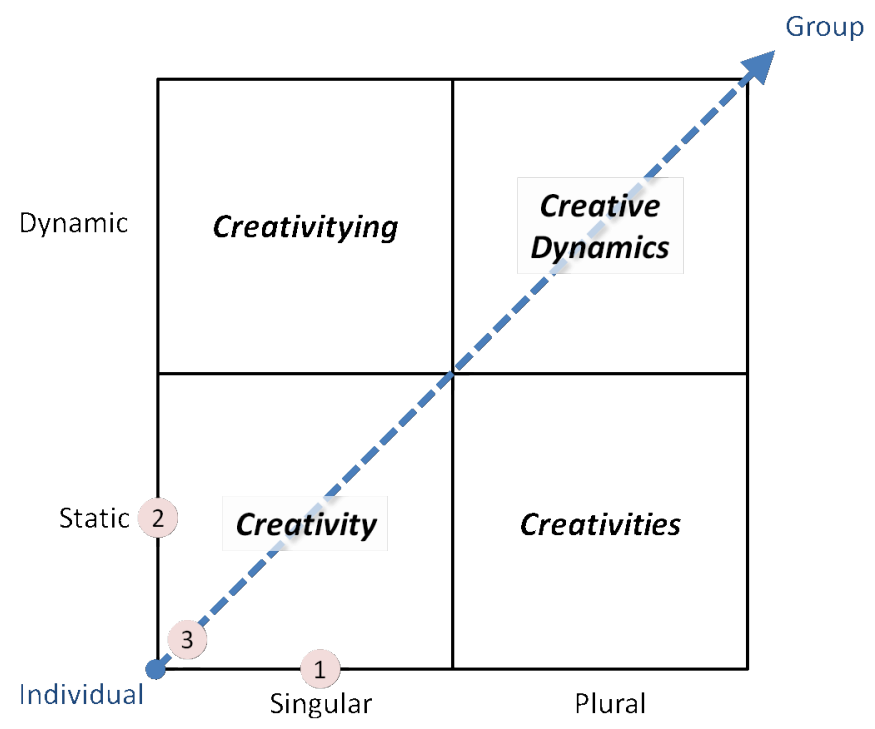

Figure 2. Creativity "squared": A creative dynamics matrix, including the positioning of the three common management assumptions about creativity

serve the processes in the Chinese office as they "matured". A key underlying assumption here was the idea that creative processes have matured in the West and that they are yet to mature (i.e., become more like current Western approaches) in "less developed" parts of the world. There must be a singular view of what best practice in creativity is, and West is (obviously) best. The reality that many of the people at the top of the world's major advertising agencies are British nationals corresponds with this view, because the British are understood to be "creative types" (more on this in point 3 below). In any event, the epiphany occurred when a third office was added to the study. This, even newer, office was in India.

If creativity was singular and there was, by association, a maturity scale, then it should simply have been a matter of plotting the Chinese and the Indian offices on this scale: except, that approach did not work. The differences between the Indian and Chinese approaches to the creative process made the student and the subjects he was observing think again. They realized that, in effect, there were three different approaches to creativity at work, and they could not be explained by being at different stages of the same singular lifecycle. They were different in kind, not degree, drawing from different mental maps and shaped by their different contexts and relationships. More than this, he saw that rather than the West informing the way the Eastern creativity should progress, it could be that each could learn from the other. 


\title{
Toward a New Understanding of Creative Dynamics
}

\author{
Stephen Cummings, Chris Bilton, and dt ogilvie
}

This story sums up the problem with the assumption that there is one type of creativity; that there is subsequently one best way to do it; and this way can be divided into discrete steps or stages that represent the evolution of the creative process. This assumption may be best illustrated if one does a Google image search for "theories of creativity". What comes up are $n$-stage frameworks that purport to explain not a process, but the process, such as:

$$
\begin{aligned}
& \text { inception } \rightarrow \text { incubation } \rightarrow \text { illumination } \rightarrow \text { realization } \\
& \rightarrow \text { verification } \\
& \text { trigger } \rightarrow \text { learn about } \rightarrow \text { incubate } \rightarrow \text { learn-by-doing } \\
& \rightarrow \text { develop know-how } \\
& \text { occupation } \rightarrow \text { incubation } \rightarrow \text { insight } \rightarrow \text { evaluation } \rightarrow \\
& \text { elaboration } \\
& \text { frame } \rightarrow \text { explore } \rightarrow \text { test and assess } \rightarrow \text { narrate } \\
& \text { preparation } \rightarrow \text { incubation } \rightarrow \text { illumination } \rightarrow \\
& \text { verification }
\end{aligned}
$$

Although these models tend to be promoted in a circular shape (perhaps because circles are seen to be more creative than straight lines, although we debate that point further on), they are still presented as a single series of steps that occur one after another. Yet, on closer inspection, some of the "stages" require different, even contradictory, modes of thinking. Such creative tensions echo Howard Gardner's theory of multiple intelligences (Gardner, 1983) and Frank Barron's (1958) argument that creative processes require "tolerance for contradictions". These contradictions (to which we will return later) are typically elided in the smooth lines of the modular creative process or cycle framed by Google images of creativity. And, although these models acknowledge the need for different competences, reflecting a move away from individualistic "trait-based" theories of creativity towards an analysis of creative teams (West, 2012) and creative systems (Csikzsentmihalyi, 1988), they still prioritize certain personal attitudes, behaviours, and talents over others, with the moment of "illumination" or "insight" taking centre stage.

The first movement in our thinking about creativity that we would like to promote here is one that re-orients us from seeking to find the single best way of (or series for) being creative, toward accepting that there may be more than one way to be creative.
So, for example, we should think more about creativity as potentially occurring throughout the value chain or network, not just at the beginning with a single originating creative idea. Indeed, we should reflect on whether activities at different stages of a value or production chain might require different modes of creativity; or whether industries or products at different phases of an industry or product lifecycle would necessitate different approaches yet again. Again, this is not just a case of breaking down a generic creative process into component parts (Zien \& Buckler, 1997) but challenging the assumption that a single set of interlocking creative competences can fit every application and every outcome. What happens when we change the sequence or reprioritize one stage in the value chain over another?

Furthermore, we have suggested elsewhere (Bilton et al., 2015) an approach based on four distinct modes of creativity - generative creativity, adaptive creativity, executive creativity, and consumer creativity - that would be useful to consider:

1. Generative creativity is the perception that creativity is primarily concerned with idea generation, and some of the assumptions (e.g., motivation, organizational behaviour and structure, education and training) that focus on this aspect of creativity (Amabile, 1998, 1990; De Bono, 1993). This is perhaps the dominant paradigm for understanding creativity in management - but we would argue that, although important, generative creativity is only one type of creativity.

2. Adaptive creativity is the under-rated but important role of adapting and improving existing ideas in order to add value (Kirton, 1984). This is a key aspect of innovation as the purposeful application of a creative idea, and it also links to the capacity among organizations and individuals to recognize and build upon an incipient creative idea. In terms of a conventional value chain, adaptive creativity is focused on the creative idea or product away from the traditional notion of creativity related to idea generation toward giving existing ideas form and substance. This approach requires a different set of skills, often more ordered than imaginative, as well as an understanding of the collective context in which creative ideas will be applied. This view is consonant with March's (1991) notion of exploitation of existing ideas. Yet, this form of creativity is often undervalued by managers - indeed the whole machinery of intellectual property law is premised on the primary importance of "originality" over adaptation. 


\title{
Toward a New Understanding of Creative Dynamics
}

\author{
Stephen Cummings, Chris Bilton, and dt ogilvie
}

3. Executive creativity highlights the importance of moving towards "proof of concept" or prototype. Executive creativity is more practically oriented towards "doing" than "thinking" and also requires a combination of pragmatism and purposefulness (as in other "creativities", the combination is internally paradoxical, as well as challenging or even contradicting the mindset and principles of other phases in the creative process described above). As Verganti points out in relation to design, radical innovation depends on the "integrative capabilities of executives" rather than the divergent thinking of individual designers (Verganti, 2009). This in turn means empowering design managers rather than seeking out the talents of individual designers (von Stamm, 2008). Very often, this kind of creativity is disparaged as "convergent" or "conventional" thinking, and the importance of this creative contribution to the overall process is routinely underestimated or dismissed outright (Bilton, 2014).

4. Consumer creativity relates to the notion that the value of a creative idea is only really apparent in the mind's eye of the beholder - this is what makes conventional creative work inherently risky and unpredictable. Increasingly, the process of consumption is not only about interpreting and re-imagining an artefact, it is a creative process in its own right (Gauntlett, 2011). Technologies and changing market structures have "empowered" consumers, and it is now possible for them to generate and distribute their own ideas without recourse to creative "professionals" (Lessig, 2008). Marketing and distribution also influence consumer creativity - reconfiguring the context in which a creative experience takes place or enabling customers to recognize and value new forms of creativity are, in themselves, modes of creativity. Consumer creativity, like design thinking, involves recognition that innovations can be initiated at the point of consumption, by radically reimagining the ways in which a product can be interpreted or used (Verganti, 2009).

Although we should expect differences between each mode, there are also different, often seemingly opposed, skills or elements at play to varying degrees within each of the four: the need for free-thinking and focus; an orientation for taking risks and knowing how to mitigate them; the value of dilettantism and structured approaches; the need for thinking abductively and clear criteria for measuring success. This is an idea that takes us back to one of the oldest, but often forgotten, theories of creativity: that creativity processes draw from the tensions between "bisociative characteristics" (Koestler, 1964); and one that we have recently used to structure (in an fairly opened-ended way) the recently published Handbook of Management and Creativity (Bilton \& Cummings, 2014). However, much more remains to be done to develop our understanding about how these different modes and differing characteristics combine to create something.

By opening ourselves up to the notion that there is no one type of creativity and no one set of creative characteristics, we may be able to move beyond the often heard refrain: "But I'm not a creative person". This statement is often used to count people out of creativity because they do not believe (or other people do not believe) that they have the conventional shared characteristics of the creative sensibility. For example, they believe that they do not possess those things outlined in Perkin's (1981) snowflake model of creativity: excellence in finding problems; mental mobility; willingness to take risks; objectivity; inner motivation; and commitment to a personal aesthetic. But, just as the idea made popular in the 1980s that there are different types of learners, so that if you were a visual learner you would struggle to learn in other ways (Gardener, 1983), or the notion popularized in the 1990s that creativity resides in the left lobe of the brain, have been superseded by views that we all benefit from multi-modality when it comes to learning and that the left side of the brain can only function to its potential when in combination with the right side and other parts, so we hope that we might recognize that creativity takes many forms and is made up of many more characteristics than those on the "snowflake". In fact, we believe that thinking of creativities rather than creativity (singular) would be a good first step in this direction.

A multimodal, bisociative approach takes us past singular models of creativity as special types of thinking or special types of person. In this context, we welcome a growing emphasis on "pluralism" and eclecticism towards theories of creativity (e.g., Kozbelt et al., 2010) and would like to see this reflected in practices of management. While both the online FreeDictionary.com and Wikipedia define the "creative person" as "a person whose creative work shows sensitivity and imagination", we wonder whether only relying on such individuals to drive creative dynamics is selling us short. Not only does this person-based approach suggest that creativity is a static property, invested in individual talent, it also implies a passive approach to managing creativity. Person-based creativity is a matter of human resources recruiting and retaining the best 


\title{
Toward a New Understanding of Creative Dynamics
}

\author{
Stephen Cummings, Chris Bilton, and dt ogilvie
}

creative "talents". "[T]his view that creativity is the province of only a few individuals pushes the organization to focus more on finding those few people than on viewing its entire workforce as a potentially creative resource" (ogilvie \& Simms, 2008). Multimodal creativity requires a more proactive approach, combining and configuring different modes of thinking and individual capabilities. We shall pick up on this idea again in the third of our proposed movements: away from creativity thought of in terms of the individual to creativity in group dynamics.

\section{Raising the Animation of Creativity: From Static Creativity to Active "Creativitying"}

One of the lessons that can be learned from the writing of Karl Weick, whom we mentioned earlier, is that organizational behaviour emerges, shifts, and changes, and takes shape over time. It is not static. And it is relational. A similar train of thought occupied the mind of Henry Mintzberg at the time that Weick's chapter outlining orientation and animation as substitutes for strategy appeared. His aim, from his first book, The Nature of Managerial Work (1973), to articles such as "Crafting Strategy" (Mintzberg, 1987), was to show that management and strategy were not solid objects. They were not best thought of as "things".

A strategy was rather something that emerged over time, as a piece of clay might become this kind or that kind of object as it was crafted by the hands of the potter; or as Weick's Hungarian soldiers in the mountains gathered momentum through action, trial, and error. It made more sense according to Mintzberg and those who surrounded him, such as strategy-process scholars including Andrew Pettigrew (1979) and those who followed up on his lead, such as the "strategy-as-practice" movement scholars (e.g., Jarzabkowski, 2005; Vaara \& Whittington, 2010; Whittington, 1996), to talk and think in terms of active verbs such as strategizing instead of static nouns such as strategy.

This idea, that all aspects of life (relationships, learning, strategy, creativity) emerge over time and are crafted in real time rather than being sedentary or following preprogrammed steps, spans a wide literature from Martin Heidegger's opus Being and Time (1962), with its focus on thinking and acting in terms of becoming rather than being, to Mathew Crawford's recent pop classic The Case for Working with Your Hands: Or Why Office Work Is Bad for Us and Fixing Things Feels Good (2010). However, we do not think it has been focused on enough in thinking about how creativity works.
Being creative is not a straightforward process. It is interactive, iterative, and messy, and most often includes small failures (Sitkin, 1992) from which the creator learns, and through her actions, creates meaning (ogilvie, 1998; Weick, 1979) by using old materials in new ways or finding new materials to use or trying new methods (Fabian \& ogilvie, 2005). Creativity in organizations is more than just coming up with a new idea, it must involve action beyond the generation of an idea, which we call "creativitying". That action can be in the form of thought experiments or in physical action to turn the idea into a reality. We view creativity as a verb, a way of doing, rather than a competence - nouns (creativity) become commodities, verbs (creativitying) are active. Creativitying, then, is action-embedded creativity. Creative leaders view creativity as an active practice or craft that involves learning through doing, failing, and re-doing. Creativitying is a group process, not the province of the lone superhero or the special few (Light, 1997; ogilvie, 1999). Research based on groups showed that creating diverse solutions and multiple solutions led to higher quality solutions (Maier, 1970; Wanous \& Youtz, 1986).

"In a world that punishes failure more than it rewards action" (Ford \& ogilvie, 1997), organizations need a new leadership model in which leaders must not only actively give their people permission to be creative, but must encourage them to do so. Ackoff (1988) sees this type of transformational leadership as an aesthetic function. Creative leaders actually need to "do things". In particular, they need to create safe environments in which they give people permission to be creative (ogilvie, 1994, 1998), to fail, learn, and succeed. They need to challenge repressive cultures and apply creativity back into the organization. Thought experiments notwithstanding, it is important for creative leaders to recognize the importance of encouraging the physical act of making something with the hands - prototypes of the creative idea. Witness the image of the sensory or motor homunculus, which is a physical embodiment showing the parts of the body in relation to their sensory or motor connections to the brain, with the hands being extremely large compared to most body parts. The ability to use our hands is a defining characteristic of humans. Using one's hands is active, not passive.

Creative leadership means that leaders give up the notion of control in the sense of command-and-control, and let creativity flow, allowing others to take the lead in their exercise of creativitying (Mumford et al., 2002; Oldham \& Cummings, 1996). The creative leader's (or leaders') role is to connect together the multiple creativ- 


\title{
Toward a New Understanding of Creative Dynamics
}

\author{
Stephen Cummings, Chris Bilton, and dt ogilvie
}

ities discussed above into a productive system. Individuals and organizations may contain many forms of creativity, as we highlighted previously. But, these creativities are often contradictory, unstable, and undirected. Without some system for aligning these creativities, there is a danger that singular creativities become destructive, either for the creative individual or for the organization as a whole.

Therefore, much as the brain controls, coordinates, or directs the execution of other programmes or routines in a cognitive system, so the creative leader reconfigures creative modes in an organizational system. The kind of leadership competences best suited to creative organizations are the ability to broker connections; accept and embrace the idea that creativity is multiple and messy and that the process is fraught with failure; believe "that everyone had the potential to be creative" but may need training to unleash that creativity (Light, 1997; ogilvie, 1999; ogilvie \& Simms, 2008); and understand that leadership in such contexts often means handing the reins to others to give them the authority to lead creativity not from the front or top of the organization, but from the middle, or even from the bottom. The creative leader not only creates a "culture of creativity" (Kelley, 1997; ogilvie \& McDaniel, 2004) that fosters conditions for creativitying by driving out fear and promoting courage, they recognize that creativity is not only about generating new ideas; it requires a series of further creative acts, creativitying, to convert the novel idea into a valuable outcome.

\section{Seeking a Prevailing Nor'Easter: From Individual Creativity to the Dynamic Creative Group}

The final assumption that we believe is holding back thinking about creativity, is the notion that, when managers think about creative acts, they tend to picture an individual being creative: an artist, a poet, a programmer, an entrepreneur, an Einstein, or an Edison. They do not tend to picture a group with different attributes becoming creative together. And, this image forms despite the fact that most creative outcomes emerge from groups or, at least, from relationships between two or more individuals, and despite over 30 years of creativity research moving away from trait-based models towards a "sociocultural paradigm" of creativity (Becker, 1982; Sawyer, 2006; Wolff, 1990).

This focus on the individual as the creative agent is not surprising given that the stage models that defined the creative process outlined in our first section were sold to individuals: the students or managers or those who sought out the pop-management books and textbooks that first emerged in the early 1980s. And, what was sought from these books by those who used them was self-improvement, not group-improvement. This tendency has been reinforced by the continuing use of individual creativity testing among human resources professionals as a mechanism for identifying and recruiting creative talent (Torrance, 1988).

A further key, one that differentiates the textbooks that emerged in this period (but which are often still in current use, in their tenth editions or beyond) from their predecessors, was the inclusion of the $n$-stage frameworks or models to capture the essential characteristics of an approach or a sub-field, in a way that brought together a large amount of information, looked scientific, and fitted nicely onto a PowerPoint slide. These frameworks were used by individuals such as management consultants and other "change agents" to analyze the behaviour of other individuals: employees, job applicants, customers, and so on.

Indeed, even those who sought to promote a more systematic, less pop-management or less introductory "textbooky" approach have kept the emphasis on the individual. Hebert Simon's (1969) dynamic framework of creativity still places "the person" and "personal creativity" at the centre of the system of "the field" and "the domain". And, whereas Michael Csikszentmihalyi's (1988) dynamic framework of creativity avoids many of the conventional traps we have outlined above, it also speaks in terms of the individual. It is "the person" that is seen to interact with the "domain" or "culture", and the "field" or "social system", not the group. Even team-based frameworks, such as Belbin's "team roles at work", are built on assumptions about individual aptitudes, locking team members into static individual job descriptions, backed up by psychological tests and predictive models of individual creative ability (Belbin, 1993; Torrance, 1988). And, it is often only these simple frameworks that students learn and managers use.

But, just as Kurt Lewin's last works $(1947,1951)$ on understanding change are generally cited only to allude to obscure fragments that are then remade into what is seen as the first and foundational change management model (unfreeze $\rightarrow$ change $\rightarrow$ refreeze), rather than one of its major points that in research into managing change the group, not the individual, should be the unit 


\title{
Toward a New Understanding of Creative Dynamics
}

\author{
Stephen Cummings, Chris Bilton, and dt ogilvie
}

of analysis, there is a danger here (Cummings et al., 2015). The danger is that, in our desire to get to the heart of creativity, we pick out fragments of earlier research to divine a simple, one-best-recipe to the exclusion of research that looks at the multiplicity and messiness of group dynamics.

More should be done to investigate the group as the creative actor. And, in so doing, we can return to the first limiting assumption that we confronted at the start of this article: the idea that creativity is the preserve of those who possess the characteristics commonly associated with creativity: imagination, sensitivity, flamboyance, eccentricity, and a disorderly or unconventional mind that sees in circles and spirals. But, as we have argued elsewhere (Bilton \& Cummings, 2010), and have already alluded to in this article, creative outcomes that add value often require the polar opposite of these things: focus, organization, diligence, planning, Gantt charts, and other straight lines.

A nice example of how these characteristic bisociate to create in group settings can be seen in the notebooks of Thomas Edison. For a time, Edison's ideas books were divided in two. Edison would scrawl out his barely legible flashes of inspiration. And then, on the facing page, an associate, such as precise and highly-organized Charles Batchelor, would work out these ideas more fully and start to plan out if and how they might be worked out and realized (Figure 3).

Edison may not have been as brilliant or eccentric or flamboyant as his competitors, such as Tesla, for example, but it is his creativity that has had the greatest impact on our lives. Edison had a good group. He knew how to combine different characters. And, he knew how to animate all of this toward outcomes that added value to people's lives. Indeed, a focus on the creative dynamics of groups enables a wider set of people and characteristics to be included in our understanding of the creative process. It is the third and final change of direction in moving our understanding from creativity as singular, devoid of time, and associated with individuals in the first instance.

\section{Conclusion}

The aim of thinking differently about creativity in the way we have outlined in this article is to recognize that creativity is not only about generating novel ideas, it often requires many and varied other types of creative acts and combinations to see a novel idea emerge or

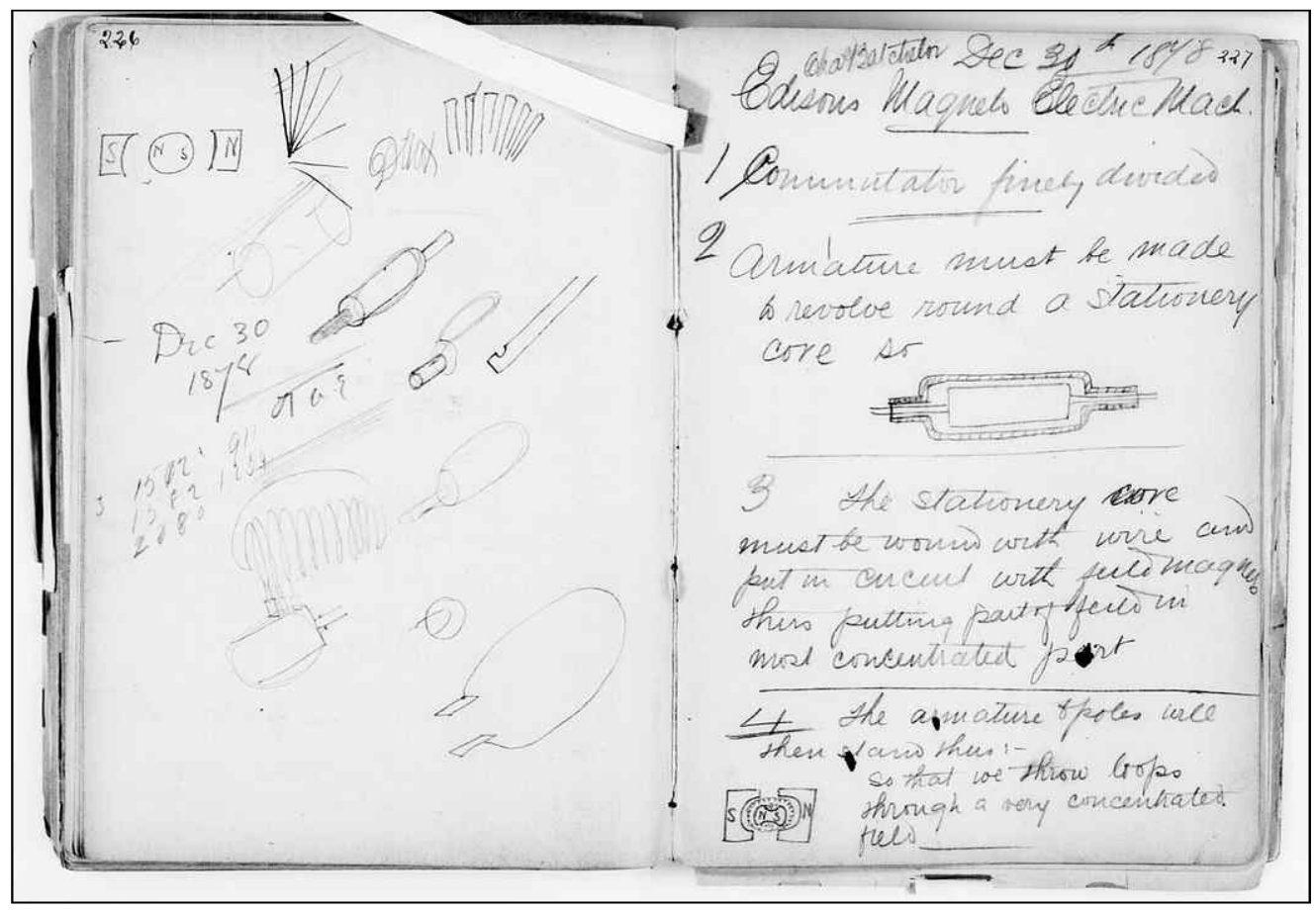

Figure 3. An excerpt from one of the Edison/Batchelor notebooks. From the digitized collection of Edison's Menlo Park notebooks at Rutgers University: http://edison.rutgers.edu/digital.htm; Notebook \#10, December 31, 1878: N-78-12-16 (1878-1879): N010228. 


\title{
Toward a New Understanding of Creative Dynamics
}

\author{
Stephen Cummings, Chris Bilton, and dt ogilvie
}

morph into a valuable outcome. Thus, we hope that the kind of thinking advocated here - multiple, dynamic, and focused on groups rather than an individual of the "creative type" - also shifts our thinking about creativity into a closer orbit with the practical outcomes of creativity (Figure 4). And, in this way, it makes it easier to think from the outcome back to the idea, rather than from what is assumed to be the start of a creative process forward. We have become so enamoured with the creativity myths surrounding the flamboyant creative genius and the lightbulb flash of inspiration, that we never fully get past what should just be the initial steps in our modelling, missing the multiplicity, the emergence, and the group dynamics that contribute to valuable creative outcomes.

Most creative outcomes come from a combination or recombination of different modes and capabilities; most creative outcomes emerge through turning thoughts into action, doing and active iteration, trying and failing, and learning and recalibrating, and getting closer; and most creative outcomes come from groups, not individuals. And, we believe that we could do well to consider this further through "squaring" our understanding of creative dynamics, as we have sought to do in the final iteration of our matrix, as we seek to further develop our knowledge of creativity in organizations.

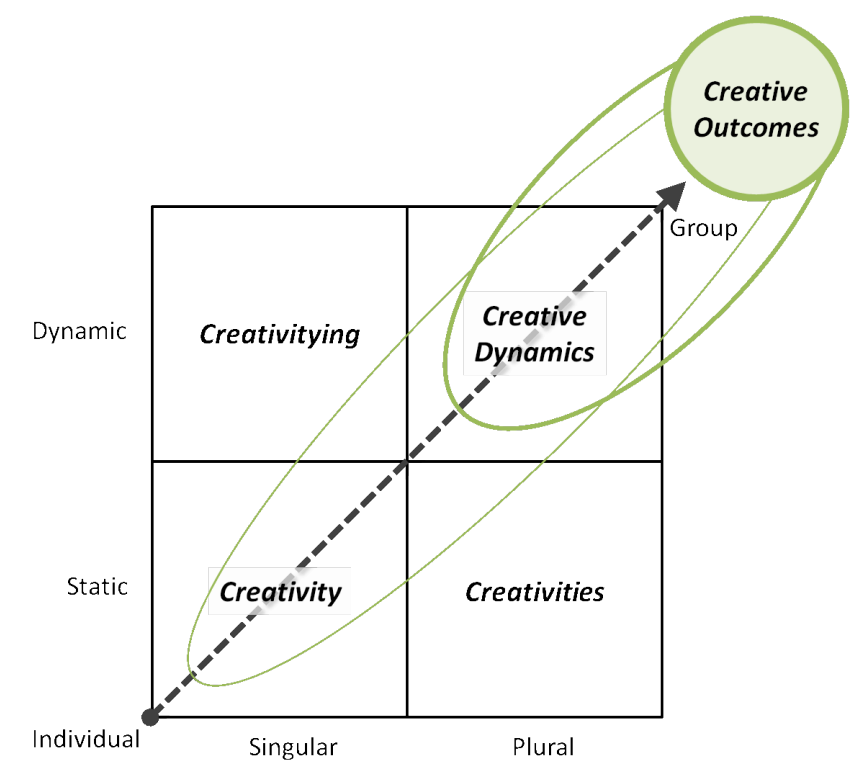

Figure 4. Creative dynamics brings our orbit closer to creative outcomes

www.timreview.ca

\section{About the Authors}

Stephen Cummings is Professor of Strategy and ICMCI Academic Fellow at Victoria Business School, Victoria University of Wellington, New Zealand. He has published on strategy, creativity, and management history in a range of journals including the Academy of Management Learning and Education Journal, Academy of Management Perspectives, Human Relations, Long Range Planning, and Organization Studies. He has also written, co-written and edited a number of books promoting creative approaches to strategy development. These include Recreating Strategy (2002), Images of Strategy (2003), Creative Strategy (2010), The Handbook of Management and Creativity (2014), and Strategy Builder: How to Create and Communicate More Effective Strategies (2015).

Chris Bilton is Reader in the Centre for Cultural Policy Studies at the University of Warwick, United Kingdom, where he specializes in management of creativity and creativity of management. He is the author, editor, and coauthor of several books on creative management and creative strategy and teaches modules on creative business and marketing. Chris has a background in theatre and in community arts, which he gained before entering the world of academia. His research interests include: leadership, strategy, and structure in creative organizations; cultural policy and the creative industries; and structure of the creative economy. He is currently working on a book about marketing in the creative industries, for publication in 2016.

dt ogilvie is Distinguished Professor of Urban Entrepreneurship and former Dean of Saunders College of Business at Rochester Institute of Technology, in New York, United States, where she founded the Center for Urban Entrepreneurship (CUE). She is formerly Professor of Business Strategy \& Urban Entrepreneurship at Rutgers Business School - Newark and New Brunswick (RBS), where she founded The Center for Urban Entrepreneurship \& Economic Development (CUEED) and the Scholarship Training and Enrichment Program (STEP). She has published in top journals and five of her research papers have been recognized with research awards. Her research interests include strategic decision making and the use of creativity to enhance business and battlefield decision making and applying complexity theory to strategy and creativity; executive leadership strategies of multicultural women executives; women in the executive suite; strategic thinking in the 21st century; cognition and strategic decision making; entrepreneurship and economic development of urban cities; and assessing environmental dimensions. 


\section{Toward a New Understanding of Creative Dynamics}

\section{Stephen Cummings, Chris Bilton, and dt ogilvie}

\section{References}

Amabile, T. 1998. Within You, Without You: The Social Psychology of Creativity, and Beyond. In M. Runco \& R. Albert (Eds.), Theories of Creativity: 61-91. Newbury Park, CA: Sage Publications.

Amabile, T. 1998. How to Kill Creativity. Harvard Business Review, September-October: $77-87$.

Anderson, N., Potočnik, K., \& Zhou, J. 2014. Innovation and Creativity in Organizations: A State-of-the-Science Review, Prospective Commentary, and Guiding Framework. Journal of Management, 40(5): 1297-1333.

http://dx.doi.org/10.1177/0149206314527128

Barron, F. X. 1958. The Psychology of the Imagination. Scientific American, 199(3): 150-169.

http://dx.doi.org/10.1038/scientificamerican0958-150

Basbøll, T. 2010. Softly Constrained Imagination: Plagiarism and Misprision in the Theory of Organizational Sensemaking. Culture and Organization, 16(2): 163-178. http://dx.doi.org/10.1080/14759551003769318

Becker, H. 1982. Art Worlds. Los Angeles: UCLA Press.

Belbin, R. M. 1993. Team Roles at Work. Butterworth/Heinemann.

Bilton, C. 2014. Uncreativity: The Shadow Side of Creativity. International Journal of Cultural Policy, 21(2): 153-167. http://dx.doi.org/10.1080/10286632.2014.892933

Bilton, C., \& Cummings, S. 2010. Creative Strategy: Reconnecting Business and Innovation. Chichester, UK: John Wiley \& Sons.

Bilton, C., \& Cummings, S. 2014. Handbook of Management and Creativity. Cheltenham, UK: Edward Elgar Publishing.

Bilton, C., Cummings, S., \& ogilvie, d. 2015. Creativitying - From Managing 'One-Size Fits All' Creativity to Leading Multiple Creativities. Professional Development Workshop, Academy of Management Conference, Vancouver, August 7-10.

Cochrane, P., Craft, A., \& Jeffery, G. 2008. Mixed Messages or Permissions and Opportunities? Reflections on Current Policy Perspectives on Creativity in Education. In J. Sefton-Green (Ed.), Creative Learning. London: Arts Council of England.

Crawford, M. 2010. The Case for Working with Your Hands: Or Why Office Work Is Bad for Us and Fixing Things Feels Good. London: Penguin.

Csikszentmihalyi, M. 1988. Society, Culture and Person: A Systems View of Creativity. In R. J. Sternberg, (Ed.), The Nature of Creativity: 325-339. Cambridge, UK: Cambridge University Press.

Csikszentmihalyi, M. 1993. The Evolving Self: A Psychology of the Third Millennium. New York: Harper Collins.

Cummings. S., and Wilson, D. 2003. Images of Strategy. Chichester, UK: John Wiley \& Sons.

Cummings, S. \& Angwin, D. 2015. Strategy Builder: How to Create and Communicate More Effective Strategies. Chichester, UK: John Wiley \& Sons.

Cummings, S., Bridgman, T., \& Brown, K. B. 2015. Unfreezing Change as Three Steps: Rethinking Kurt Lewin's Legacy for Change Management. Human Relations (forthcoming).

De Bono, E. 1993. Serious Creativity: Using the Power of Lateral Thinking to Create New Ideas. London: Harper Collins.
Fabian, F. \& ogilvie, d. 2005. Strategy as Art: Using a Creative ActionBased Model for Strategy Formulation. In S. W. Floyd, J, Roos, C. D. Jacobs, \& F. W. Kellermanns (Eds.), Innovating Strategy Processes: 57-71. Malden, MA: Blackwell Publishing.

Ford, C. M., \& ogilvie, d. 1997. An Action-Based Approach to Business Education. Career Development International, 2(2): 80-84. http://dx.doi.org/10.1108/13620439710163662

Gardner, H. 1983. Frames of Mind: The Theory of Multiple Intelligences. New York: Basic.

Gauntlett, D. 2011. Making is Connecting: The Social Meaning of Creativity, from DIY and Knitting to YouTube and Web 2.0. Cambridge: Polity Press.

Heidegger, M. 1962. Being and Time. 1927. Trans. John Macquarrie and Edward Robinson. New York: Harper.

Jarzabkowski, P. 2005. Strategy as Practice: An Activity Based Approach. London: Sage.

Kirton, M. 1984. Adapters and Innovators - Why New Initiatives Get Blocked. Long Range Planning, 17(2): 137-143. http://dx.doi.org/10.1016/0024-6301(84)90145-6

Koestler, A. 1964. The Act of Creation. London: Hutchinson.

Kozbelt, A., Beghett, R., \& Runco, M. 2010. Theories of Creativity. In J. Kaufman and R. Sternberg (Eds.), The Cambridge Handbook of Creativity: 20-47. New York: Cambridge University Press.

Lessig, L. 2008. Remix: Making Art and Commerce Thrive in the Hybrid Economy. London: Bloomsbury.

Lewin, K. 1947. Frontiers in Group Dynamics: Concept, Method and Reality in Social Science; Equilibrium and Social Change. Human Relations, 1(1): 5-41.

Lewin, K. 1951. D. Cartwright (Ed.) Field Theory in Social Science: Selected Theoretical Papers. New York: Harper \& Row.

March, J. 1991. Exploration and Exploitation in Organizational Learning. Organization Science, 2(1): 71-87. http://dx.doi.org/10.1287/orsc.2.1.71

Mintzberg, H. 1973. The Nature of Managerial Work. New York: Harper \& Row.

Mintzberg, H. 1987. Crafting Strategy. Harvard Business Review, July: 66-75.

Mumford, M. D., Scott, G. M., Gaddis, B., Strange, J. M. 2002. Leading Creative People: Orchestrating Expertise and Relationships. The Leadership Quarterly, 13(6): 705-720. http://dx.doi.org/10.1016/S1048-9843(02)00158-3

ogilvie, d. 1994. The Strategic Decision Making Process: Using Imagination to Improve Solutions in Unstable Environments. Unpublished doctoral dissertation. The University of Texas at Austin.

ogilvie, d. 1998. Creative Action as a Dynamic Strategy: Using Imagination to Improve Strategic Solutions in Unstable Environments. Journal of Business Research, 41(1): 49-56. http://dx.doi.org/10.1016/S0148-2963(97)00011-8

ogilvie, d. 1999. Book Review of Paul C. Light Sustaining Innovation. Nonprofit and Voluntary Sector Quarterly, 28(3): 350-355. 


\section{Toward a New Understanding of Creative Dynamics}

\section{Stephen Cummings, Chris Bilton, and dt ogilvie}

ogilvie, d., \& Hauge, F. 1999. Decision Making Requirements for Future Organizational Leaders: A Creative Action-Based Approach. In J. G. (Jerry) Hunt, G. E. Dodge, \& L. Wong (Eds.), Out-of-the-Box Leadership: Transforming the 21st Century Army and Other TopPerforming Organizations: 63-89. Westport, CT: JAI Press.

ogilvie, d., \& McDaniel, R. R. Organizational Creativity and Complexity: Balancing on the Edge of Chaos. Presented at the 2004 Strategic Management Society Annual Conference, San Juan, PR, 31 October - 4 November 2004.

ogilvie, d., \& Simms, S. 2008. The Impact of Creativity Training on an Accounting Negotiation. Group Decision and Negotiation, 18(1): 75-87. http://dx.doi.org/10.1007/s10726-008-9124-z

Oldham, G., \& Cummings, A. 1996. Employee Creativity: Personal and Contextual Factors at Work. Academy of Management Journal, 39(3): 607-634.

http://dx.doi.org/10.2307/256657

Perkins, D. N. 1981. The Mind's Best Work. Cambridge, MA: Harvard University Press.

Pettigrew, A. M. 1979. On Studying Organizational Cultures. Administrative Science Quarterly, 24(4): 570-581.

http://dx.doi.org/10.2307/2392363

Prichard, C. 2002. Creative Selves? Critically Reading 'Creativity' in Management Discourse. Creativity and Innovation Management, 11(4): 265-276.

http://dx.doi.org/10.1111/1467-8691.00258

Sawyer, R. K. 2006. Explaining Creativity: The Science of Human Innovation. Oxford: Oxford University Press.
Simon, H. A. 1996. The Sciences of the Artificial. (Original edition 1969). Cambridge, MA: MIT Press.

Sternberg, R. 1988. A Three-Facet Model of Creativity. In R. Sternberg (Ed.), The Nature of Creativity: Contemporary Psychological Perspectives: 125-147. Cambridge, UK: Cambridge University Press.

Swieringa, R. J., \& Weick, K. E. 1982. An Assessment of Laboratory Experiments in Accounting. Journal of Accounting Research Supplement: Studies on Current Research Methodologies in Accounting: A Critical Evaluation, 20: 56-101. http://dx.doi.org/10.2307/2674675

Vaara, E., \& Whittington, R. 2012. Strategy-as-Practice: Taking Social Practices Seriously. The Academy of Management Annals, 6(1): 285-336. http://dx.doi.org/10.1080/19416520.2012.672039

Verganti, R. 2009. Design-Driven Innovation. Boston, MA: Harvard Business School Press.

Von Stamm, B. 2008. Managing Innovation, Design and Creativity. Chichester, UK: Wiley.

Weick, K. E. 1987. Substitutes for Strategy. In D. J. Teece (Ed.) The Competitive Challenge: Strategies for Industrial Innovation and Renewal: 222-233. Cambridge, MA: Ballinger.

Whittington, R. 1996. Strategy as Practice. Long Range Planning, 29(5): 731-735. http://dx.doi.org/10.1016/0024-6301(96)00068-4

Zien, K., \& Buckler, S. 1997. From Experience Dreams to Market: Crafting a Culture of Innovation. Journal of Product Innovation Management, 14(4): 274-287.

http://dx.doi.org/10.1111/1540-5885.1440274

Keywords: creativity, creativities, creativitying, action-embedded creativity, creative dynamics, management, innovation 